1. BDS, M.Phil (Anatomy) Lecturer Anatomy PDC

2. BDS, M.Phil (Oral Biology) Assistant Professor Oral Biology PDC.

3. BDS, FCPS (Endodontics) Associate Professor Operative Dentistry

RCD

4. MBBS, M.Phil (Anatomy) Assistant Professor Anatomy PMC

5. MBBS, M.Phil (Anatomy) Assistant Professor Anatomy PMC.

6. MBBS, M.Phil (Anatomy) Assistant Professor Anatomy PMC

Correspondence Address:

Dr. Ambereen Humayun

Department of Anatomy

PDC.

ambereenhumayun@yahoo.com

Article received on:

24/12/2019

Accepted for publication:

25/03/2020

\section{ESTIMATION OF THE FREQUENCY OF SECOND MESIOBUCCAL ROOT CANAL IN MAXILLARY FIRST PERMANENT MOLAR TEETH IN SUBJECTS VISITING TEACHING DENTAL HOSPITALS OF PESHAWAR.}

Ambereen Humayun', Munawar Aziz Khattak², Aamir Mehmood Khan ${ }^{3}$, Nighat Ara ${ }^{4}$, Farooq Khan ${ }^{5}$, Noman Ullah Wazir ${ }^{6}$

ABSTRACT... Objectives: To determine the frequency of second mesiobuccal canal (MB2) in a sample of 223 extracted maxillary permanent $1^{\text {st }}$ molars. Study Design: In-vitro Cross-sectional study. Setting: Department of Endodontic at Peshawar Dental Hospital. Period: June 2019Nov 2019. Material \& Methods: The samples were processed with application of the Clearing Technique which includes demineralization with nitric acid, dehydration with ethanol and clearing with methyl salicylate. The samples were classified according to Weine's system of root canal classification. Results: Among the 223 samples, 30\% were found to have Weine's type1 root canal in the mesiobuccal root (second mesiobuccal canal absent). Second mesiobuccal canal was present in majority of the samples (70\%) with Weines type2 (2-1) predominant with $23.32 \%$, Weines type3 (2-2) present in $15.7 \%$ and Weines type 4 (1-2) present in $21 \%$ of the samples. $9 \%$ of the samples could not fit into Weines classification so they were placed in Vertuccis classification for root canal system type 6 (2-1-2). Conclusion: The present study concludes that the second mesiobuccal canal is more frequently found in maxillary permanent $1^{\text {st }}$ molar teeth than our textbooks report, irrespective of quadrant and gender. Therefore, time should be given to evaluation of its anatomy by the clinician before starting the root canal treatment for the greater good of the community.

Key words: $\quad$ Clearing Technique, Endodontic, MB2, Quadrant, Root Canal.

Article Citation: Humayun A, Khattak MA, Khan AM, Ara N, Khan F, Wazir NU. Estimation of the frequency of second mesiobuccal root canal in maxillary first permanent molar teeth in subjects visiting teaching dental hospitals of Peshawar. Professional Med J 2020; 27(10):2203-2209.

DOI: $10.29309 / T P M J / 2020.27 .10 .4439$

\section{INTRODUCTION}

A good understanding of the anatomy of the root canal of a tooth plays a pivotal role for the success of endodontic treatment. Dentists must have a thorough knowledge of the normal tooth anatomy and the possible anatomical variations to have a better outcome of the endodontic treatment. ${ }^{1}$ Lack of knowledge leads to inadequate shaping and cleaning of the root canal resulting in posttreatment disaster, mostly happens in cases where a tooth has a morphological deviation from its normal anatomy. ${ }^{2,3}$

Maxillary $1^{\text {st }}$ molar is the largest sized tooth with the most complicated root as well as root canal anatomy. It is the most effected tooth which is least understood due to the presence of its second mesiobuccal canal which is often missed during root canal therapy. ${ }^{4}$ This tooth commonly consists of three roots and canals i.e. Mesiobuccal root and canal, Distobuccal root and canal and Palatal root and canal. However in the mesiobuccal root of this tooth, a canal located in the palatal portion of the root might get missed/ overlooked. This canal is widely known as the second mesiobuccal canal (MB2)..$^{5}$ Maxillary first molars frequently need endodontic therapy due to higher caries incidence as it is the first permanent tooth to erupt, having large surface area and negligence to care at younger age..$^{6,7}$ The second mesiobuccal root canal of maxillary first molar remains the biggest mystery in endodontics. ${ }^{4}$ An inability to detect and then treat a second mesiobuccal root canal may be the main reason for endodontic failure in maxillary $1^{\text {st }}$ molar teeth. ${ }^{8}$ The mesiobuccal root of the maxillary permanent $1^{\text {st }}$ molars is frequently treated surgically with the highest failure ratio. ${ }^{9}$ The MB2 orifice is located 
often mesial to or in the pulpal groove that connects the main MB canal to the palatal canal, $3.5 \mathrm{~mm}$ palatally and $2 \mathrm{~mm}$ mesial to the main $\mathrm{MB}$ canal. ${ }^{4}$ Locating the MB2 canal is thus a challenge for the clinician in achieving successful treatment of maxillary molars, therefore, if the prevalence of the MB2 canal is high in a population, time should be devoted to its anatomy for better treatment. ${ }^{10}$

Anatomy of pulp systems varies hugely in different races and in different individuals and within the same race and Internal complexities of the root canal are genetically determined and have great importance in anthropology, thus necessitating the identification of root canal morphologies of different ethnic populations. ${ }^{11}$ The frequency of MB2 canal in a Saudi sub population was found to be $70.6 \%{ }^{12}, 65 \%$ frequency in Indian population of Meghalaya region, ${ }^{11} 58.4 \%$ in Iranian population ${ }^{13}$, $63.6 \%$ presence in Thai population ${ }^{14}$ and $85 \%$ in Turkish population. ${ }^{15} 45 \%$ frequency of MB2 canal was found in another study done on a Saudi sub population ${ }^{16}$ and (28\%) from another study done on Indian population. ${ }^{17}$

Various techniques have been used to study root canals of teeth i.e. Cone-beam-computedtomography, sectioning, radiography, scanning electron microscopy, root canal staining and clearing technique etc. I chose root canal staining and clearing method due to its cost-effectiveness, ease of use, not requiring advanced facility \&equipment.

The aim of the present study is to report the frequency of the second mesiobuccal root canal in permanent maxillary $1^{\text {st }}$ molar teeth in a sample population of patients visiting the three teaching dental hospitals of Peshawar.

This study will help the clinicians in improving the therapeutic strategies for the greater benefit of the community. The clinician will get aware of the high frequency of the second mesiobuccal canal in maxillary first molars in our population and will be careful in looking for MB2 canal while performing root canal treatment. The general public will thus be benefited due to the better outcome of the treatment.

\section{MATERIAL \& METHODS}

This study was an in-vitro cross-sectional study extended over a period of 06 months from June 2019 to November 2019. It was based upon a sample population of 223 extracted maxillary $1^{\text {st }}$ permanent molar teeth of males and females from the oral and maxillofacial surgery departments of three teaching dental hospitals of Peshawar i.e. Khyber College of Dentistry, Sardar Begum Dental College and Peshawar Dental College. Non-probability convenience sampling technique was used for collection of the samples. Teeth with deep caries, fracture, incompletely formed roots or damage to root morphology during extraction and teeth with metallic restorations were excluded from the study.

The samples were stored in $5.25 \%$ sodium hypochlorite for 30 minutes for the removal of organic debris, and afterwards in $10 \%$ formalin until use. Each tooth was cleaned under running water and dried in air. Access cavities were prepared with air turbine high-speed hand piece and diamond burs and the coronal pulp tissue was wiped out from the orifices of canals. Indian ink was then injected into the root canals of each tooth using 24 gauge needles.

After the ink dried i.e. 24-48hrs, each tooth was stored in 5\% nitricacidfor05 days. Demineralization was assessed by inserting a paper pin into the crown. Each tooth was rinsed for 04 hours under running water and afterwards placed in 70, 80 and $95 \%$ ethanol for dehydration for 01 day. By the end of this duration, no opacity remained. The clearing procedure was completed by placing the samples of extracted teeth in methyl salicylate for 1-3 days. At the end of the third day, complete transparency was achieved. ${ }^{18-19}$

Root canal morphology was examined with the naked eye by a single examiner. Data was recorded in pre-structured data collection proformas. Root canal anatomy was categorized and documented according to Weine's system for classification of root canal morphology. Statistical analysis was done using statistical package for social sciences version 19. The frequency of the second mesiobuccal canal was computed. Chi- 
square test was applied for categorical variables such as gender and site. Probability value of less than 0.05 was considered statistically significant.

\section{RESULTS}

Sixty seven (30\%) extracted Maxillary First Molars (MFMs) out of a total of 223 MFMs were found to have a single canal in the mesiobuccal root (Weines type1 canal configuration) as shown in Figure-2.

Second mesiobuccal canal (MB2) was found in majority of the participants being present in the mesiobuccal root of one hundred and fifty six extracted MFMs (70\%). Weine's type2 canal configuration (Figure-3) was the most frequent type being present in fifty two MFMs (23.3\%). Weines type 3 canal configuration (Figure-4) was found in thirty five MFMs (15.7\%). Weines type 4 canal configuration (Figure-5) was found in forty seven MFMs (21.1\%).

Twenty two MFMs (9.9\%) had a canal configuration which could not be classified into Weines types, so they were placed in Others (Figure-6) i.e. Vertuccis type 6 (Vertucci's classification for root canal configuration) as shown in Figure-1.

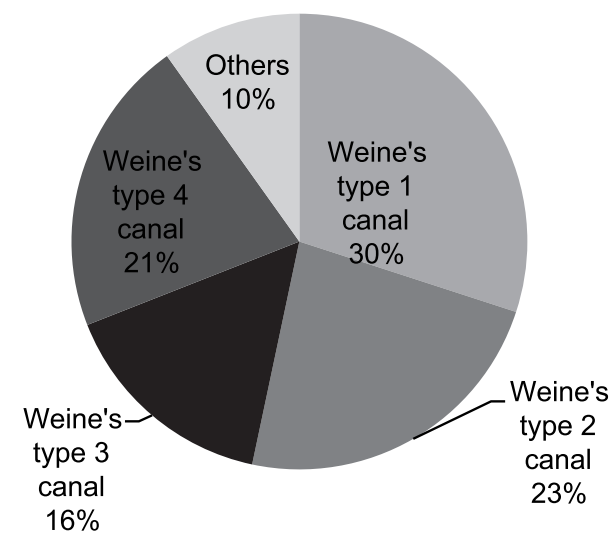

Figure-1. Frequency distribution of the types of MB (mesiobuccal) canal.

Among 82 male (82 teeth) participants of the study, 25 male MFMs had one canal present in the mesiobuccal (MB) root so MB2 canal was absent (30.5\%). While 57 male MFMs had two canals in the MB root so MB2 canal was present (69.5\%).
Among these 82 male MFMs, 25 teeth (30.5\%) had Weines type $1 \mathrm{MB}$ canal configuration (MB2 absent). 13 teeth (15.9\%) had Weines type2 MB canal configuration i.e. 2canals-1foramen. 14 teeth $(17.1 \%)$ had Weines type $3 \mathrm{MB}$ canal configuration i.e. 2canals-2foramina. 21 teeth (25.6\%) had Weines type $4 \mathrm{MB}$ canal configuration i.e. 1 canal-2 foramina and 9 teeth (10.9\%) had other type of MB canal configuration which could not be classified into Weines types, so they were placed in Vertuccis canal classification type 6 i.e. 2 canals- 1 canal- 2 foramina.

Among the 141 female participants of the study, 42 female MFMs had one canal in the MB root so MB2 canal was absent (29.8\%). 99 female MFMs had MB2 canal present in the MB root (70.2\%).

Among these 141 female participants, 42 (29.8\%) female MFMs had Weines type 1 MB canal configuration (MB2 canal absent). 39 female MFMs (27.7\%) had Weines type $2 \mathrm{MB}$ canal configuration. 21 female MFMs (14.9\%) had Weines type $3 \mathrm{MB}$ canal configuration, 26 female MFMs (18.4\%) had Weines type $4 \mathrm{MB}$ canal configuration and lastly 13 female MFMs (9.2\%) had other canal configuration which could not be classified into Weines types so they were placed in Vertuccis canal classification type 6 i.e. 2-1-2.

No statistically significant difference was found between gender and presence of MB2 canal $(p=$ 0.911 ), nor to the canal configuration when chisquare test was applied $(p=0.320)$ as shown in Table-l.

Of the total 223 MFMs, 118 MFMs belonged to the right quadrant. Out of these 118 right-sided MFMs, 36 MFMs had only one canal in the MB root (MB2 canal absent, Weines type 1 canal configuration) (30.5\%). 82 right MFMs had MB2 canal present in the MB root (69.5\%).

Of the 105 left-sided MFMs, 31 MFMs had MB2 canal absent, Weines type 1 canal configuration (29.5\%). While, 74 MFMs had MB2 canal present (70.5\%).

Among the 118 right-sided MFMs, Weines type2 
canal configuration was found in 22 MFMs (18.6\%). Weines type 3 canal configuration was found in 25 MFMs (21.2\%). Weines type4 canal configuration was found in 23 MFMs (19.5\%). Other canal configuration was found in 12 MFMs $(10.2 \%)$.

Out of 105 left-sided MFMs, 30 MFMs had Weines type 2 canal configuration (28.6\%). Weines type
3 canal configuration was found in 10 MFMs (9.5\%). Weines type 4 canal configuration was found in 24 MFMs (22.9\%). Other type of canal configuration was found in 10 MFMs (9.5\%).

No statistically significant difference was found on application of chi-square test between quadrant of the tooth and the presence of MB2 canal as shown in Table-Il.

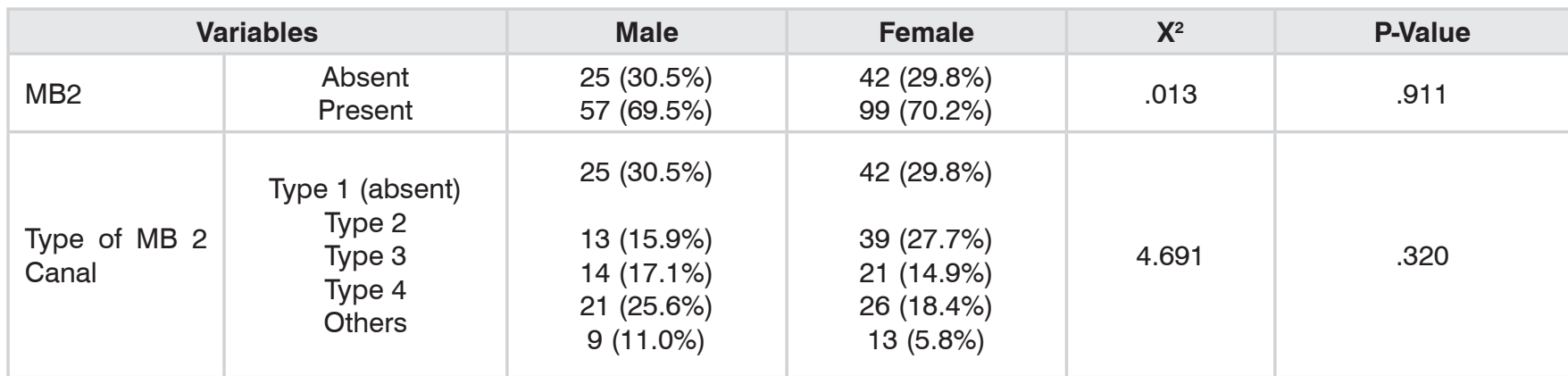

Tablel. Gender-based frequency distribution of MB (Mesiobuccal) canal.

\begin{tabular}{|c|c|c|c|c|c|}
\hline \multicolumn{2}{|c|}{ Variables } & \multirow{2}{*}{$\begin{array}{c}\text { Right } \\
46(56.1 \%) \\
72(51.1 \%)\end{array}$} & \multirow{2}{*}{$\begin{array}{c}\text { Left } \\
36(43.9 \%) \\
69(48.9 \%)\end{array}$} & \multirow{2}{*}{$\frac{\mathbf{X}^{2}}{.527}$} & \multirow{2}{*}{$\begin{array}{c}\text { P-Value } \\
.468\end{array}$} \\
\hline Gender & $\begin{array}{c}\text { Male } \\
\text { Female }\end{array}$ & & & & \\
\hline Type of MB 2 Canal & $\begin{array}{c}\text { Type } 1 \text { (absent) } \\
\text { Type } 2 \\
\text { Type } 3 \\
\text { Type } 4 \\
\text { Others }\end{array}$ & $\begin{array}{l}36(30.5 \%) \\
22(18.6 \%) \\
25(21.2 \%) \\
23(19.5 \%) \\
12(10.2 \%)\end{array}$ & $\begin{array}{c}31(29.5 \%) \\
30(28.6 \%) \\
10(9.5 \%) \\
24(22.9 \%) \\
10(9.5 \%)\end{array}$ & 8.2 & 0.08 \\
\hline
\end{tabular}

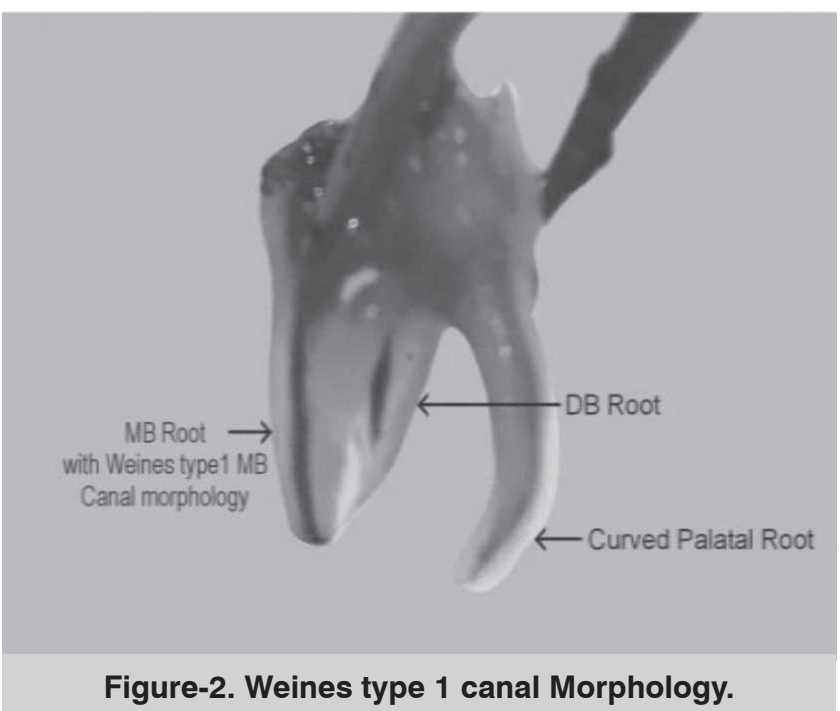

Professional Med J 2020;27(10):2203-2209.

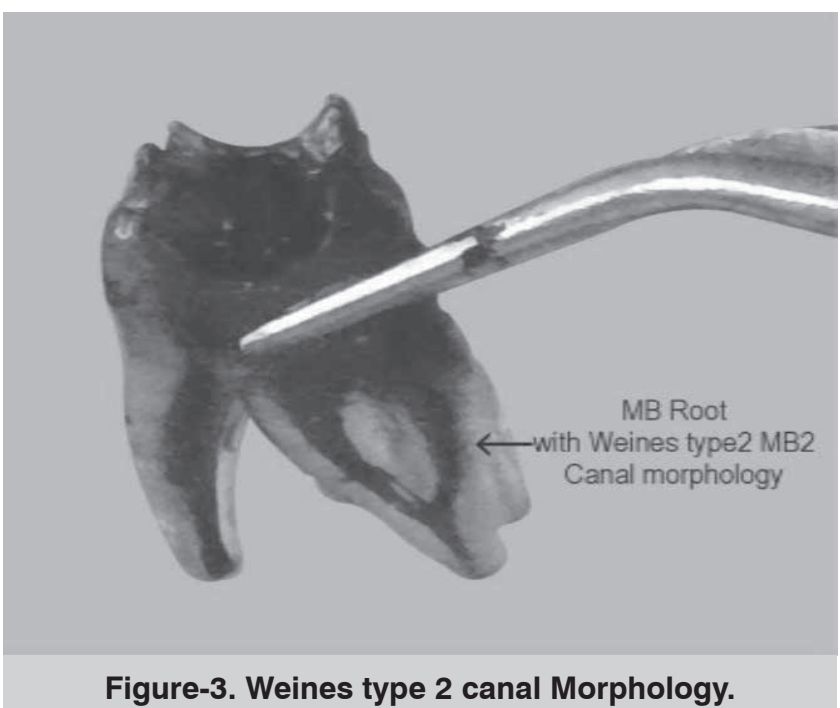

Figure-3. Weines type 2 canal Morphology. 


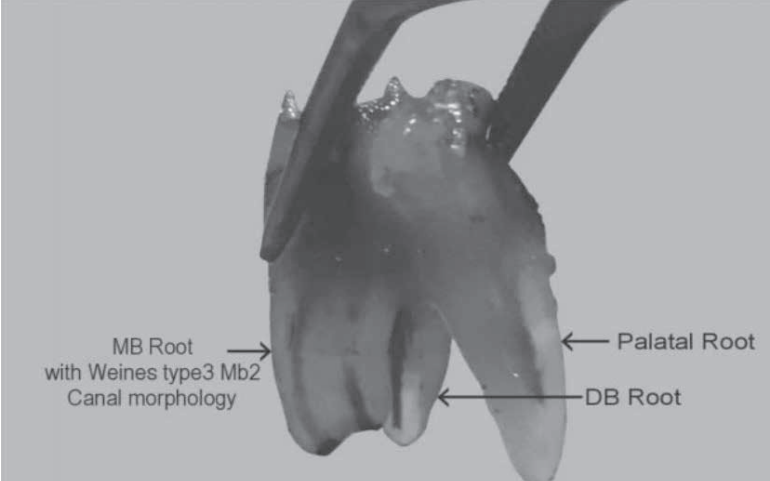

Figure-4. Weines type 3 canal Morphology.

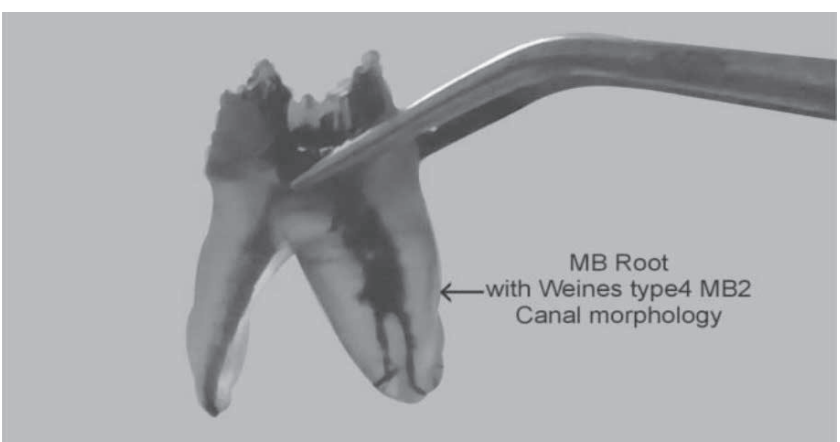

Figure-5. Weines type 4 canal morphology.

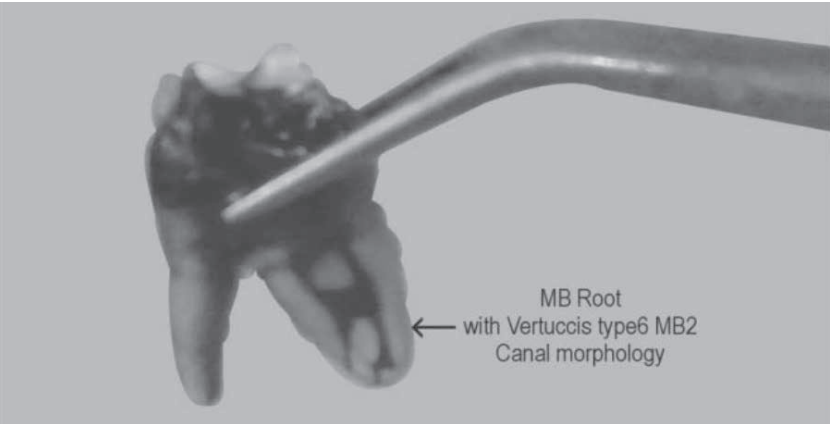

Figure-6. Others (Vertuccis type 5 canal morphology).

\section{DISCUSSION}

In the present study, second mesiobuccal canal (MB2) was found in $70 \%$ of the sample population of 223 extracted maxillary first molar teeth which is comparable with other studies in literature that were carried out in American and Indonesian populations. ${ }^{20}$

The present finding $(70 \%)$ is lower than the findings of various studies in literature that were carried out in Sri-Lanka $(77 \%)^{22}$, in Japanese population $(80.9 \%)^{23}$ and in Turkish population (85\%). ${ }^{15}$ In the present study of extracted maxillary first molars, Weines type2 canal (two canals and one foramen) was found to be the most frequent type of second mesiobuccal canal (MB2) in the mesiobuccal root which is in accord with a study carried out in Turkish population. ${ }^{24}$ In Thai, Irish, Japanese, Indian and Sri-Lankan populations, the prevalent type of MB2 canal in maxillary first molars was found to be Weines type3 (two canals, two foramina) which the authors designate as Vertuccis type4. ${ }^{25,26,23,11,22}$ These differences might be due to different geographical location, racial, genetic and cultural differences.

In this study, no significant gender-based difference was found regarding the presence of second mesiobuccal canal in the sample of extracted permanent first maxillary molars which supports the findings of a previously done study in the United States of America ${ }^{27}$, but contradicts the finding of another study stating that gender plays a role in the presence of a second mesiobuccal canal in MFMs and that male MFMs has a higher percentage of a second mesiobuccal canal in their mesiobuccal root. $^{28}$

In the present study, no significant difference was found on the basis of tooth position (right or left quadrant) in the morphology of upper first molars which supports the findings of other studies in literature. ${ }^{29,27}$ A study done on a dental school population in America stated that aberrant root morphology in a given tooth is most of the time present in the corresponding contralateral tooth as well. ${ }^{30}$

\section{CONCLUSION}

This study concludes that the second mesiobuccal canal is very frequently (up to $70 \%$ ) present in the mesiobuccal root of maxillary permanent first molars irrespective of gender or quadrant of the tooth.

Thus, time and effort should be put by the clinician to examine and understand thoroughly the anatomy of the upper first molar tooth before undertaking any clinical procedure especially the root canal treatment to minimize the risk of missing any extra-canal/s present thus, lowering the chance of failure of the endodontic treatment 
that often leads to tooth-loss/extraction ultimately. Copyright@ 25 Mar, 2020.

\section{REFERENCES}

1. Kalhoro F. A. Validity of different methods for MB2 canal location in permanent maxillary molars. 2014; 34(3):548-551.

2. Hasan M, Umer F. Endodontic retreatment of a mandibular first molar with five root canal systems: An important clinical lesson. Case Reports. 2014; 2014(mar20 1):bcr2013201402-bcr2013201402. doi:10.1136/bcr-2013-201402.

3. Tuncer AK, Haznedaroglu F, Sert S. The location and accessibility of the second mesiobuccal canal in maxillary first molar. Eur J Dent. 2010; 4(1):12-16. http://www.pubmedcentral.nih.gov/articlerender.fcgi artid $=2798784 \&$ tool $=$ pmcentrez\&rendertype $=a b$ stract.

4. Das S, Warhadpande M, Redij S, Jibhkate N, Sabir H. Frequency of second mesiobuccal canal in permanent maxillary first molars using the operating microscope and selective dentin removal: A clinical study. Contemp Clin Dent. 2015; 6(1):74. doi:10.4103/0976237X.149296.

5. Coelho MS, Lacerda MF, Silva M. Locating the second mesiobuccal canal in maxillary molars : Challenges and solutions. Clin Cosmet Investig Dent. 2018:195202.

6. Bhardwaj VK. Dental caries prevalence in individual tooth in primary and permanent dentition among 6-12-year-old school children in Shimla, Himachal Pradesh. Int J Heal Allied Sci. 2014; 3(2):125-128. doi:10.4103/2278-344X.132700.

7. Demirci M, Tuncer S, Yuceokur AA. Prevalence of caries on individual tooth surfaces and its distribution by age and gender in university clinic patients. Eur $\mathrm{J}$ Dent. 2010; 4:270-279.

8. Corbella S, Del Fabbro M, Tsesis I, Taschieri S. Computerized tomography technique for the investigation of the maxillary first molar mesiobuccal root. Int $\mathrm{J}$ Dent. 2013; 2013(September). doi:10.1155/2013/614898.

9. Rathi S, Patil J, Jaju PP. Detection of mesiobuccal canal in maxillary molars and distolingual canal in mandibular molars by dental CT: A Retrospective Study of 100 Cases. Int J Dent. 2010; 2010:1-6. doi:10.1155/2010/291276.
10. Peeters HH, Suardita K, Setijanto D. Prevalence of a second canal in the mesiobuccal root of permanent maxillary first molars from an Indonesian population. J Oral Sci. 2011; 53(4):489-494. doi:10.2334/josnusd.53.489.

11. Bhuyan A, Kataki R, Phyllei P, Gill G. Root canal configuration of permanent maxillary first molar in Khasi population of Meghalaya: An in vitro study. J Conserv Dent. 2014; 17(4):359. doi:10.4103/0972-0707.136511.

12. Alrahabi M, Zafar MS. Evaluation of root canal morphology of maxillary molars using cone beam computed tomography. PJMS. 2015; 31(2):426-430.

13. Shahi S, Yavari HR, Rahimi S, Ahmadi A. Root canal configuration of maxillary first permanent molars in an Iranian population. J Dent Res Dent Clin Dent Prospects. 2007; 1 (1):1-5. doi:10.5681/joddd.2007.001.

14. Ratanajirasut R, Panichuttra A, Panmekiate S. A conebeam computed tomographic study of root and canal morphology of maxillary first and second permanent molars in a Thai. J Endod. 2017:1-6. doi:10.1016/j. joen.2017.08.020.

15. Demirbuga S, Sekerci AE, Dinçer AN, Cayabatmaz M, Zorba YO. Use of cone-beam computed tomography to evaluate root and canal morphology of mandibular first and second molars in Turkish individuals. Med Oral Patol Oral Cir Bucal. 2013; 18(4):737-744. doi:10.4317/medoral.18473.

16. Agwan AS, Sheikh Z, Dh D, Rashid H. Canal configuration and the prevalence of second mesiobuccal canal in maxillary first molar of a Saudi sub-population. Journal of the Pakistan Dental Association. 2015 Oct;24:182-7.

17. Singh S, Pawar M. Root canal morphology of South Asian Indian maxillary molar teeth. Eur J Dent. 2015; 9(1):133. doi:10.4103/1305-7456.149662.

18. Hasselgren G, Tronstad L, Odont $L$. The use of transparent teeth in the teaching of preclinical endodontics. J Endod. 1975; 1(8):278-280.

19. Robertson D, Leeb IJ, McKee M, Brewer E. A clearing technique for the study of root canal systems. $J$ Endod. 1980; 6(1):421-424. doi:10.1016/S00992399(80)80218-4.

20. Pomeranz HH, Fishelberg G. The secondary mesiobuccal canal of maxillary molars. J Am Dent Assoc. 1974; 88(1):119-124. doi:10.14219/jada.archive.1974.0045. 
21. Sykaras SN, Economou PN. Root canal morphology of the mesiobuccal root of the maxillary first molar. Odontostomatol Proodos. 2011; 24(2):99-108. http://eutils.ncbi.nlm.nih.gov/entrez/eutils/elink.fcgi?dbfrom =pubmed\&id $=20880136 \&$ retmode $=$ ref $\& \mathrm{cmd}=$ prlinks .

22. Peiris R, Oman R, Force A. Mesiobuccal root canal morphology of the permanent maxillary first molar in a Sri Lankan population. 2012; 34(2):36-44.

23. Imura N, Hata Gl, Toda T, Otani SM, Fagundes MI. Two canals in mesiobuccal roots of maxillary molars. Int Endod J. 1998; 31(6):410-414. doi:10.1111/j.13652591.1998.0169.x.

24. Çalişkan MK, Pehlivan Y, Sepetçio-lu F, Türkün M, Tuncer SŞ. Root canal morphology of human permanent teeth in a Turkish population. J Endod. 1995; 21(4):200-204. doi:10.1016/S0099-2399(06)80566-2.

25. Alavi AM, Opasanon A, Gulabivala K. Root and canal morphology of Thai maxillary molars. 2002:478-485.
26. Al Shalabi RM, Omer OE, Glennon J, Jennings M, Claffey NM. Root canal anatomy of maxillary first and second permanent molars. Int Endod J. 2000; 33(5):405-414. doi:10.1046/j.1365-2591.2000.00221.x.

27. Neaverth EJ, Kotler LM, Kaltenbach RF. Clinical investigation (In Vivo) of endodontically treated maxillary first molars. October. 1987; 13(10):506-512.

28. Fogel HM, Peikoff MD, Christie WH. Canal configuration in the mesiobuccal root of the maxillary first molar: Clinical study. J Endod. 1994; 20(3):135-137.

29. Kim Y, Lee S-J. Morphology of maxillary first and second molars analyzed by СВСТ in a korean population: Variations in the number of roots and canals and the incidence of fusion. JOE. 2012; 38:1063-1068. doi:10.1016/j.joen.2012.04.025.

30. Sabala CL, Neas BR. Bilateral root or root canal aberrations in a dental school patient population. J Endod. 1994; 20(1):38-42. doi:10.1016/S0099-2399(06)800257.

\begin{tabular}{|c|c|c|c|}
\hline \multicolumn{4}{|c|}{ AUTHORSHIP AND CONTRIBUTION DECLARATION } \\
\hline Sr. \# & Author(s) Full Name & Contribution to the paper & Author(s) Signature \\
\hline 2 & $\begin{array}{l}\text { Ambereen Humayun } \\
\text { Munawar Aziz Khattak }\end{array}$ & $\begin{array}{l}\text { Conception and design, } \\
\text { Acquisition of data. } \\
\text { Drafting of work. }\end{array}$ & \\
\hline 3 & Aamir Mehmood Khan & Critical review of the work. & \\
\hline 4 & Nighat Ara & $\begin{array}{l}\text { Final approval fo the version } \\
\text { to be published. }\end{array}$ & \\
\hline 5 & Farooq Khan & $\begin{array}{l}\text { Analysis and interpretation } \\
\text { of the data. }\end{array}$ & \\
\hline 6 & Noman Ullah Wazir & Final review. & \\
\hline
\end{tabular}

